\title{
LEFT-BRANCH EXTRACTION AS OPERATOR MOVEMENT: EVIDENCE FROM CHILD DUTCH\{PRIVATE \}
}

Jacqueline van Kampen, UiL OTS, Utrecht University

\section{INTRODUCTION}

The present paper deals with left-branch extractions in child language not supported by the adult input. These left-branch extractions appear in wh-questions (example (1)a), topicalizations (example (1)b) and scrambling environments (example (1)c).
a. welke wil jij [e liedje] zingen? which want you [e song] sing?
(which song do you want to sing?)
b. Cynthia is dat niet [e pyama] Cynthia is that not [e pyama] (That is not Cynthia's pyama)
c. dat heb ik zo niet meer [e lang] gedaan! that have I so not more [e long] done! (I have not done that for a long time)

This paper is organized as follows. Section 2 exemplifies the left-branch extractions in Dutch child language and raises the learnability question. Section 3 gives some additional facts that are relevant for the analysis of left-branch extractions in child language. Section 4 settles some questions about the categorial status of the subextracted elements. Section 5 takes a look into the present day analyses of left-branch extractions. Section 6 discusses the problem of a learning scenario for obligatory pied piping. Section 7 wonders whether universal LF representations might explain the child's long-standing preferences for the set of non-adult PF realizations. Section 8 serves as a conclusion.

\section{FACTS AND LEARNABILITY QUESTION}

\subsection{Left-branch wh-extractions in child Dutch}

Wh-movement in Dutch child language may shift the left-branch element, leaving behind a nominal or adjectival projection (Hoekstra and Jordens 1994), as in the examples (2)-(3).m]1 This construction is not found in the adult input.

\footnotetext{
1.The examples are from 130 audio-recordings of my two daughters, Sarah (50 recordings; age range 1;7-5;5) and Laura (80 recordings; age range $1 ; 9-6 ; 0)$ and from diary notes. The transcripts of the recordings contain 24.127 analyzable utterances of Laura and 16.546 analyzable utterances of Sarah. The total number of finite sentences with realized wh-element is 263 in the Laura files and 370 in the Sarah files. The diary notes contain 1.659 utterances of two words and more of Laura and 873 utterances of Sarah. The total number of finite sentences with realized wh-element is 92 in the diary notes of Laura and 47 in the diary notes of Sarah. The material will be, and has already partially been, incorporated in CHILDES. The audio-recordings have been transcribed in CHAT format. The left-branch extractions that have been found in the corpora were uttered at the following ages: Sarah (S.): between 2;9 and 6;4/Laura (L.): between 2;6 and 8;4 (age in <years;months.days>). Jacomine Nortier has provided me with some additional data of her daughters Emma and Loura, Nienke Bijholt of her sons Joep and Tim, Peter Coopmans of his son Tim and Wim Zonneveld of his daughter Nina. Jeannette Schaeffer's experiments on the acquisition of scrambling in Dutch, yielded several left-branch extractions by Dutch children aged 3;7-3;9. See Hoekstra and Jordens (1994) for more Dutch examples, and Penner (1993) for Swiss German ones.
} 
(2) Stranding the nominal projection
a. welk wil jij [e boekje]?
which want you [e booklet]?
(which booklet do you want to read?)
b. welke wil jij [e liedje] zingen?
which want you [e song] sing?
(which song do you want to sing?)
c. $\{$ kom kijken\} hoeRianne [e veel plezier] heeft! (Loura 6;6) \{come and see\} how Rianne [e much fun] has! (come and see how much fun $\mathrm{R}$. is having!)
d. welke wil je [e chocolaatjes]?
which want you [e chocolates]?
(which chocalates do you want?)

(3) Stranding the adjectival projection
a. \{mag ik proeven\} hoe het [e heet] is? \{may I taste\} how it [e hot] is? (may I taste how hot it is?)
b. hoe is het [e laat]? how is it [e late]? (how late is it?)
c. ik weet niet hoe het [e lang] is I know not how it [e long] is (I do not know how long it is)
(Tim C. 3;6/
Loura 6;5)
(Emma 3;1/
Loura $3 ; 6$ )

The wh-extractions in (2)-(3) violate the Left-Branch Condition (Ross 1967). Ross's condition generalizes over the ungrammaticality of examples like (2) and (3) in adult Dutch. Movement of an element - determiner, degree word, possessor - in the left-branch position is possible only by pied piping the entire phrase.

The figures in (4) represent the distribution of complex wh-phrases in the Laura and Sarah recordings and diary notes.
a. $\quad$ No pied piping (stranding)
recordings
diary notes
11
Laura $(2 ; 9-5 ; 6)$
7
Sarah $(2 ; 9-5 ; 2)$
17
4
b. Pied piping (no stranding)
Laura $(2 ; 9-5 ; 6)$
Sarah $(2 ; 9-5 ; 2)$

recordings
4
11
diary notes
4
2

The number of complex wh-phrases is not very high if one compares it to the total number of utterances with a wh-element (see endnote 1). This is due to the fact that children prefer simple wh-pronouns (Lebeaux 1988, Radford 1986). Since complex phrases do not occur frequently in 
early child language, statistics of the left-branch violations are not significant. The distribution in the files, though, shows that left-branch extractions ((4)a) occurred more often than pied piping $((4) b)$ at the age indicated.

\subsection{Left-branch <-wh> extractions in child Dutch: topicalization and scrambling}

The sentence-initial position may be occupied by a subextracted $<-$ wh $>$ pronoun as well, witness the examples in (5) from Hoekstra and Jordens (1994).

(5) Topicalization of the left-branch element

Stranding the nominal projection
a. die heb ik niet [e sok] aan that have I not [e sock] on (I am not wearing that sock)
b. Cynthia is dat niet [e pyama] Cynthia is that not [e pyama] (that is not Cynthia's pyama)

(Jasmijn 2;3)

(Jasmijn 2;5)

Another kind of $<-$ wh $>$ subextraction is found in sentences where a pronoun is in a scrambling position at the left of a negative or positive adverb, as in the examples in (6) and (7).

(6) Scrambling of the left-branch element

Stranding the nominal projection
a. ik wil die niet [e boek] lezen!
I want that not [e book] read! (I do not want to read that book)
b. doejij Laura's ook [e haar]? do you Laura'stoo [e hair]? (are you fixing Laura's hair too?)
c. e is andere nou [e puzzel]? $\mathrm{e}$ is other then [e puzzle]? ((where) is the other puzzle?)
d. Cynthia mag mij niet [e navel] zien Cynthia may mynot [e belly button] see (Cynthia is not allowed to see my navel)

(7) Scrambling of the left-branch element

Stranding the adjectival projection
a. is heel wel [e lekker]!
is very indeed [e nice]!
((that) is very nice indeed)
b. dat heb ik zo niet meer [e lang] gedaan! that have I so not more [e long] done! 
(I have not done that for a long time)

c. waarom moet dat $z o$ nog [e heet]?

(Tim B. 3;5)

why must that so yet [e hot]?

(why does it have to be that hot yet?)

In the following sections I will use the distinction $<+$ wh $>/<-w h>$ element. Later on, in section 7 , I will define left-branch extractions in topicalizations and scrambling environments as $\}$-movement triggered by $<+$ focus $>$.

\subsection{The learnability question: The acquisition of the Left-Branch Condition}

The subextractions of the previous section all violate Ross's Left-Branch Condition. The LeftBranch Condition is not a universal constraint. It does not apply in certain adult languages such as Polish, Russian and Latin. Moreover, the D-elements in these languages are (i) highly inflected (Ross 1967:131) and (ii) optional (Uriagereka 1988:113, Corver 1990:332). An example is the whsubextraction in Polish in (8) from Corver (1990:330).

$$
\begin{aligned}
& \text { jaki }_{\mathrm{i}} \quad \text { wykreciles } \\
& \text { which } \\
& \text { (which number did you dial? } \text { ) }
\end{aligned}
$$

Rizzi gives the Italian example of subextraction from an AP (Rizzi 1990b:36) in (9)a, although Italian lacks nominal inflection. Identical subextractions from AP are allowed in South American Spanish (Butt and Benjamin 1988, Sergio Baauw p.c.), cf. the example in (9)b.
a. quanto $\mathrm{i}_{\mathrm{i}}$ è $\quad$ alto $\mathrm{t}_{\mathrm{i}}$ ]?
how is (he) tall?
(how tall is he?)
b. cómo somos desgraciadas las mujeres!
how are(we) unhappy the women!
(how unhappy we women are!)

The observations by Ross lead to the central problem of this paper, formulated in (10).

(10) How is the Left-Branch Condition acquired?

a. Which parameter setting yields the Left-Branch Condition, that is which parameter setting forces pied piping?

b. Why does the learner of Dutch start with a grammar that tends to disregard the LeftBranch Condition?

Question (10)a will be discussed in section 6. I will argue there that the Left-Branch Condition is a $\mathrm{PF}$ adjacency condition on Case assignment. Question (10)b will be discussed in section 7. The 
result subextraction of reminds of reconstruction at LF. I propose, as an answer to (10)b, that the child may start of with the LF representation as a computationally more economic setting.

Before turning to these main questions, I will mention a few additional facts (section 3 ) and define the categorial status of the subextracted element (section 4). Section 5 presents a sketch of current standard solutions.

\section{ADDITIONAL FACTS}

Several phenomena can be related to both the $<+w h>$ and the $<-w h>$ subextraction facts. They are enumerated in (11) and elaborated below.

(11) a. Pied piping, i.e. movement of the entire phrase, is a simultaneous option from the beginning.

b.Stranding data are still found, and are not uncommon, after the age of six, when the obligatory presence of D-elements has already been acquired for more than two years.

c. In the recordings there are no examples of violations of the Condition on Extraction Domains (Huang 1982).

d. The subextracted elements seem to bear contrastive stress.

I will illustrate these facts below, beginning with observation (11)a. Pied piping of the wh-phrase follows subextraction quite soon, but at first only as a less frequent option. See the examples in (12).m]2

(12) Wh-movement of the entire projection
a. [welk boek] ga jij top lezen?
[which book] go you tDP read?
(which book are you going to read?)
b. [welke lepel] wil jij tDP hebben?
[which spoon] want you t $t_{D P}$ have?
(which spoon do you want to have?)
c. [hoe laat] is het tDegP?
[how late] is it $t_{\text {DegP }}$ ?
(how late is it?)

Pied piping in early Dutch also occurs for topicalized and scrambled elements.

(13) Topicalization of the entire projection

a. [deze man] gaat top eruit

[this man] goes $t_{D P}$ out of it

(this man goes out of it) 
b. [jouw lamp] is tDP niet op de fiets

[your lamp] is $t_{\mathrm{DP}}$ not on the bike

(your lamp is not on the bike)

c. [mijn roosie] heb je $t_{\mathrm{DP}}$ vergeten

[my little rose] have you $t_{D P}$ forgotten

(you have forgotten to bring my little rose)

d. [heel moeilijk] ga ik een huis $t_{\text {DegP }}$ bouwen

[very complicated] go I a house t $t_{\text {DegP }}$ built

(I am going to built a house in a very complicated way)

(14) Scrambling of the entire projection
a. ik heb [zo een] nog niet tDP
I have [such one] not yet $t_{D P}$
(I have not such a thing yet)
b. ik kan [mijn eigen] niet top dragen
I can [my own] not top carry
(I cannot carry myself)

Let me turn to the second fact (11)b. Left-branch extraction gradually disminishes.m]3 Nevertheless, it remains a persistent phenomenon, witness the examples in (15).
a. hoeveel
denk je
dat ik [e geld]
heb?
how much do you think that I [e money] have?
(how much pocket money do you think I have?)
b. hoeveel krijg ik dan [e zakgeld]?
how much get I then [e pocket money]?
(how much pocket money will I get then?)

The observation in (11)b is supported by the fact that $<+/-$ wh $>$ subextractions in Dutch child language extend far into the period in which the obligatory use of articles, demonstratives, interrogatives, and genitive marking is well-established in the child grammar (cf. the ages in (15)). This is a clear difference with Latin and Polish in which D-elements remain an option. Significantly, these languages do not have articles, whereas Dutch does have articles and Dutch child language shows the systematic use of articles long before the left-branch extractions disappear. Consider the examples in (16).

\footnotetext{
3.As I have said in section 2.1, statistics of the left-branch violations are not significant. But there is a little decrease in left-branch violations if one compares the first year (roughly 3;0-4;0) with the second year (roughly $4 ; 0-5 ; 0$ ) for both children. Sarah: First year: $31,25 \%$ pied pipings//68,75\% left-branch extractions. Second year: $65 \%$ pied pipings//35\% left-branch extractions. After the age of 5;0 left-branch extractions become less frequent. Laura: First year: 34\% pied pipings//67\% left-branch extractions. Second year: 75\% pied pipings//25\% left-branch extractions. After the age of 5;4 left-branch extractions become less frequent. It would be highly relevant if more data were available to get reliable percentages. Nevertheless, it is de facto true that Dutch child language shows long-lasting left-branch violations that disappear completely in adult Dutch.
} 
(16) a. waarom wil jij dat in de auto zetten?
why want you that in the car put?

(why do you want to put that in the car?)

b. mijn jurk is nat van dit water

my $<+$ gen $>$ dress is wet from this water

(my dress is wet from this water)

c. de volgende keer ga ik mijn brood opeten

the next time go I my<+gen $>$ bread eat

(next time I will be eating my bread)

At the age of 3.5 the children are using already articles, demonstratives and genitive marking. I assume that they recognize these elements as functional heads, because they use them in adult-like fashion. Nevertheless, left-branch violations still occur.

The observation in (11)c is exemplified in (17) and (18). The $<+$ wh $>$ and $<-$ wh $>$ subextractions in Dutch child grammar involve only direct object DPs and predicative DegPs. Utterances like those in (17) and (18) probably do not occur in child language.

(17) Extraction out of a subject
a. *welk leest [DP $e$ kind] een boekje? which reads [DP e child] a booklet?
b. *dat leest [DP $e$ kind] een boekje which reads [DP e child]a booklet

(18) Extraction out of an adjunct
a. *hoe heeft de kat [DegP $e$ hoog] gesprongen?
how has the cat [DegP e high] jumped?
b. *zo heeft de kat [DegP $e$ hoog] gesprongen
that has the cat [DegP e high] jumped

There were 8 examples of subject/adjunct $<+$ wh $>$ movement in the Laura and Sarah files. All show pied piping of the full constituent, $\mathrm{cf}(19)$.
a. welk meisje is $t_{w h}$ dan jarig?
which girl is $t_{\mathrm{wh}}$ then celibrating her birthday?
(which girl celebrates her birthday then?)
b. welke dieren komen $t_{\mathrm{wh}}$ dr allemaal?
which animals come $t_{\mathrm{wh}}$ there all?
(which animals will all come?)
c. weet je hoeveel nachtjes ze $t_{w h}$ jarig is
do.y.know how many nights she $t_{\mathrm{wh}}$ is celibrating her birthday?
(do you know in how many nights she celebrates her birthday?)


This is reminiscent of the CED effects (Condition on Extraction Domains, Huang 1982) of adult grammars.m]4 Adverbial phrases and subject DPs constitute islands for extraction, since they are not L-marked (Chomsky 1986, 1995:79)m]5

The last point $((11) \mathrm{d})$ is illustrated by the stress pattern in (20). In the cases of subextraction, the stress lies on the subextracted element rather than on the complement.

$$
\begin{aligned}
& \text { waarom moet dat zó nog }[e \text { heet }] \text { ? } \\
& \text { why must that so yet }[\text { hot }] \text { ? } \\
& \text { (why does it have to be that hot yet?) }
\end{aligned}
$$

Neutral stress falls to the right, i.e. on the most governed head (Cinque 1993a). Other patterns in which the main stress falls on one of the other heads, are marked as special. The special stress on the subextracted may be a crucial factor for the left-branch extractions in child language, as I will argue in section 7.2.

\section{THE CATEGORIAL STATUS OF THE SUBEXTRACTED ELEMENTS}

The longstanding option between left-branch extractions and pied piping supports the view that subextracted elements are based on a functional $<+/-$ wh $>$ feature from the very beginning (Van Kampen 1994). Let us assume that the functional category $\mathrm{D}^{\circ}$ and $\mathrm{Deg}^{\circ}$, as well as its specific form, which is $\{<+d>/<+w h>\}$, belong to a universal set of functional categories accessible to the language learner a priori. It stands to reason that a learning procedure will be necessary to identify the universal $<+d>/<+w h>$-categories in their language-specific disguise. The phonological form, at least, is not given as a universal.

The $<+/-$ wh $>$ element must have been identified as a functional head quite early. Single whpronoun questions appear long before the left-branch extractions or pied pipings. The identification of the $<+\mathrm{wh}>$ pronoun (hoe 'how', welke 'which', wie 'who', wat 'what') as a functional category $\mathrm{D}^{\circ}$ or $\mathrm{Deg}^{\circ}$ has to be fairly straightforward. The language learner first produces simple question words only (wat 'what', waar 'where', wie 'who').m]6 The wh-element is in sentence-initial scope position, i.e. it is a $<+w h>$ marked operator. Moreover, it contains no

4.Clearly, the overall number of utterances with subject and adjunct movement is not very high. The present analysis would gain in plausibility if more data were available. The only counterexample I found is the one in (i), extraction out of a temporal adjunct.

(i)

$$
\begin{aligned}
& \text { dat heb ikzó niet meer [e lang] gedaan! } \\
& \text { that have I só not more [e long] done! } \\
& \text { (I have not done that for a long time) }
\end{aligned}
$$

(Loura 6;6)

\footnotetext{
For the moment, I tentatively adhere to the analysis since I have found no counterexamples in the recordings and since it fits the theoretical picture. Adult languages that may violate the Left-Branch Condition obey the CED as well (Corver 1990:334).

5.There is a difference between subextraction out of DegP in predication structures, as in (3) and (7), and subextractions out of DegP in adjunct positions, as in (18). Only in the latter case do we have a DegP barrier. I derive the subextractions in (3) and (7) by assuming that copular verbs Lmark their complement. This assumption is contrary to the one made in Chomsky (1986:78). See Van Kampen (1997) for an additional argument. 6.In English child language wh-elements also appear first as wh-pronouns rather than as wh-phrases, see Radford (1986:67) and Lebeaux (1988:443).
} 
further information than the typical phi-features allow (Lebeaux 1988:444). In the same vein, the D-elements die/dat 'that', mij 'my' and the Deg-elements zo 'so'/heel 'very' (see examples in section 2.2) have all the properties of functional, closed class elements and may be identified by the learner as such in a straightforward way.m]7

I follow here Emonds' (1985:191) characterization, in which grammaticalized (functional) categories have the properties paraphrased in (21).

(21) a. They are closed class elements and belong to a class that contains a small set of words which can't be added on to (no conscious coining).

b. They differ only by syntactic features and cannot be differentiated from each other solely by purely semantic features.

Wh-elements, articles and demonstratives are in general mutually exclusive.m $] 8$ They compete for a single $\mathrm{D}^{\circ}$ position and this restriction is respected in child language. The language acquisition device (LAD) must have recognized these elements as functional categories.

The Polish wh-elements, exemplified in (8), are equally straightforwardly captured as functional elements by Emonds' characterization. The same may be said of Rizzi's (1990b:36) degree element in the example Quanto è alto? in (9)a. They trigger wh-movement, allow optional pied piping and have no more content than the $<+w h>$ feature plus perhaps additional phi-features. I conclude that subextractions leave a gap $t_{D} / t_{\text {Deg }}$ that is recognizable for the LAD.

\section{LEFT-BRANCH VIOLATIONS AS ANALYZED IN PRESENT DAY SYNTAX}

Ross's Left-Branch Condition has been reconsidered in Uriagereka (1988:113) and Corver (1990). They propose more or less the same type of analysis. Corver (1990) presents the most elaborate one. Roughly speaking and not entering into a set of subtilities (for these see Corver 1990:329ff), one might reinterpret Corver as follows. The $<+/-w h>$ left-branch element is subject to a parameter $<+/-$ projecting $>$, in the spirit of Fukui and Speas (1986, cf. Uriagereka 1988). If the $<+/-$ wh $>$ element is $<+$ projecting $>$ we get a Dutch/German type of language. If the $<+/-w h>$ element is $<-$ projecting $>$ we get a Polish type of language. The left-branch element is in Polish analyzed as an adjunction to the N-projection. Moreover, the left-branch element is a maximal

\footnotetext{
7.The classification of the wh-elements, demonstratives, possessives and quantifiers in (2), (5) and (6) as $\mathrm{D}^{\mathrm{o}}$ is quite common for the functional categories (see Corver 1990:34, Demske 1995 and Chomsky 1995:263,282 for recent examples). The same may be said of the classification of the wh-elements and modifiers in (3) and (7) as Deg (Corver 1990:41). I extend $\mathrm{D}^{\circ}$ to proper names. They have clear parallels with demonstratives as non-characterizing identifiers and they fit the present subextraction pattern, cf. the examples in (5)b and (6)b,d (See Van Kampen 1997:33 for the idea that proper names serve as an identifier for $\mathrm{D}^{\circ}$ in acquisition). I assume as well that the child interprets andere in (6)c as a quantifying $\mathrm{D}^{\circ}$ (comparable to many in adult languages, see Abney 1987:290f).

8.For expository reasons I will abstract away from split DP and split DegP. See Szabolsci (1983), Abney (1987), Cinque (1993b), Giusti (1995), Longobardi (1996) and De Wit (1997) for some complications and some proposals for a split DP/DegP. A split analysis is not relevant to the main points of the analysis proposed here. My basic claim is that all subextracted single elements are functional heads within an extended N- or Aprojection and that they appear as operators.
} 
projection as in (22).m]9

a.

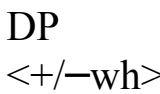

$<+/-\mathrm{wh}>$ b.

AP

$$
\begin{aligned}
& \text { DegP } \\
& <+/- \text { wh }>
\end{aligned}
$$

AP

Hoekstra and Jordens (1994) assume this kind of adjunction structure for child language.m]10 As long as this structure holds the $<+d>\mid<+w h>$ element may be subextracted if its containing NP is L-marked. It now follows that in Polish as well as in child language, subextraction is possible out of an object constituent, and not possible out of a subject or an adjunct. After all subjects and adjuncts are not L-marked.

As soon as the language learner recognizes articles, he/she will identify the left-branch element as a variant of the functional $<+$ projecting $>$ category $\mathrm{D}^{\circ} / \mathrm{Deg}^{\mathrm{o}}$. The adjunction structure will be reanalyzed as in (23).
a.
DP
b.
DegP
$\mathrm{D}^{\mathrm{o}}$
$<+/-\mathrm{wh}>$
NP
$\operatorname{Deg}^{0}$
AP
$<+/-w h>$

The $\mathrm{D}^{\circ} / \mathrm{Deg}^{\mathrm{o}}$ head cannot be extracted due to (relativized) Minimality (Rizzi 1990b, Chomsky 1995:81). It cannot cross its L-governor. The Left-Branch Condition becomes relevant now and pied piping of the full constituent is the only way to move the left-branch element into the sentence-initial operator position.

All of this is according to the facts. A nice point of these analyses is that they fit well with Chomsky's (1995) analysis of X-bar structure. Chomsky (1995:chapter 4) states that a chain should obey the three requirements in (24) by definition.
a. Uniformity (either heads or maximal constituents)
b. C-command
c. A feature checking trigger

The left-branch element which does not project must be $<-$ projecting/ +maximal $>$. Hence, it has entrance to the Spec C. If a subextracted element lands into this position, it allows a chain that satisfies Chomsky's conditions. Firstly, the chain is uniform as <-projecting/+maximal $>$ (requirement (24)a). Secondly, the chain is build on c-command since its head Spec,C ccommands its point of the tail in the object position (requirement (24)b). Thirdly, the chain is caused by the attempt to get a check in Spec, $\mathrm{C}$ of the $<+/-w h>$ operator feature against a feature

9.DP in (22) stands for $<-$ projecting $><<+$ maximal $>$.

10.In fact, the adjoined projection is lexical in Corver (1990) and Hoekstra and Jordens (1994). but that is irrelevant for the point I make here. 
$<+\mathrm{Q}>/<+$ topic $>$ in $\mathrm{C}^{\mathrm{o}}$ (requirement (24)c).m]11

The contention that the subextracted elements are maximal projections is therefore supported by the structure-preserving uniformity of chain condition combined with the checking condition. Corver (1990) applies a somewhat different terminology but the fundamental difficulties of leftbranch subextraction are clearly pointed out in his analysis.

It seems then that the wh-subextraction in Dutch child language fits into the present day ideas about generative syntax. For some of my readers this may be sufficient as a reassurement.

\section{THE LEARNING SCENARIO}

\subsection{The current analysis}

There is a tension between the current analysis sketched in section 5 and a plausible learning scenario. A closer look at the learning scenario for the category D may raise doubt about the plausibility of Hoekstra and Jordens's (1994) account of $<+/-w h>$ extraction in Dutch child language. The crucial step in their analysis of left-branch extraction is a switch made by the language acquisition device (the LAD). At first the LAD analyzes the left-branch element as a functional category that is not projecting. The $<+/-w h>$ element is adjoined to an N-projection during that period and it can be considered as an adjunct that is a maximal projection in its own right, see diagram (22). Then there is a point of reconsideration and thereafter, the $<+/-$ wh $>$ element is analyzed as an item that projects and takes its NP companion as a kind of complement rather than being adjoined to it. This is a remarkable change of the input parsing performed by the LAD. In the first place, the LAD must assume that functional categories may or may not project. Then, for some reason, it will take the decision that the category $\mathrm{D}$ is not projecting. This decision turns out to be the correct one for the Polish type of languages and the incorrect one for the German type of languages. The early decision of a non-projecting D-element causes the correct left-branch extractions in Polish and the incorrect left-branch extractions in Dutch and German child language. Subsequently, there is new evidence in the Dutch/German type of languages. This evidence comes in late, but is so strong that the LAD can retreat from its early but mistaken assumption that the functional category D in Dutch/German type of languages is not projecting. This would be the general outline of a learning scenario for the Left-Branch Condition in Dutch/German.

The assumption of a plus/minus parameter for the projection of functional categories fits explanations by Rizzi (1990b), Chomsky (1995:chapter 1.4.1). It follows from Minimality that an adjunct DP as in Polish may be subextracted out of an L-marked constituent, whereas a projecting head D in Dutch/German may not be subextracted and will bring about pied piping. Be this as it may, the current analysis may rely on Minimality, but requires a retreat from $<-$ projecting $>$ into $<+$ projecting $>$.

Let me try to get a different view on the matter. Extraction of heads out of governed constituents is not unheard of. Baker's (1988) incorporation cases may come to the mind.m]12

11.See also Rizzi (1990a).

12.For clitic movement as long head movement see De Rivero (1991), Roberts (1994). 
Suppose then that functional heads may be extracted from L-marked constituents. Then we do not need the plus/minus parameter for the projection of functional categories, which might be a good thing anyway. It frees us from an almost impossible switching learning scenario and it allows a more uniform analysis of functional categories. Diagram (23) is relevant for all languages. The Delement always projects as DP and it is a $<+\mathrm{N}>$ element, sharing such categorial features with its lexical complement. Pied piping is now a far more limited question. Why will the D-element in the German type of language never strand its N-complement and apply pied piping obligatory? This is a learning issue since the D-element in the Polish type of languages may strand its $\mathrm{N}$-complement and not apply pied piping. Uriagereka (1988) as well as Corver (1990) notice, but do not derive, that languages with obligatory pied piping will have articles. This is a remarkable coincidence. Without further explanation one might as well expect no correlation at all, or even the reverse claim. That would be the (de facto) completely incorrect claim that only languages without articles have obligatory pied piping.

The following derivation seems to me plausible. Languages with articles may be looked upon as languages that have an obligatory D-element in all N-projections. Why should some languages, Dutch/German e.g., require a D-element in (almost) all N-projections, whereas other languages have these D-elements as free additions only? A plausible answer might be that all N-projections require Case. Some languages use the D-elements as the Case carriers, whereas others allow autonomous Case on the N-element. The type with real Case on the D-element will need a Delement in each N-projection that should satisfy the Case Filter. Hence, such a language needs a kind of dummy D-element and this naturally is the article. The languages with autonomous Case on the N-element will have no use for an obligatory D-element and hence they will lack articles. The evidence for the obligatory presence of D-elements is overwhelming and hence learnable. The same must hold for optional presence and autonomous Case marking on the N-element. The articles in Dutch child language appear in a regular way long before the acquisition of pied piping. At the moment I am still busy to get more precise data, but to get an impression about the enormity of the gap, articles may be in place around the age of 3 and pied piping becomes a more or less reasonably adhered to principle around the age of 5 .

This leads me to the following three difficult questions.

a. How is it possible to (sub)extract the head $\mathrm{D}<+/-\mathrm{wh}>$ in adult Polish and in Dutch child language?

b. What is the landing site of the subextracted head $\mathrm{D}<+/-$ wh $>$ ?

c. If child Dutch allows subextraction of the head $\mathrm{D}<+/-$ wh $>$ and yet satisfies the Case Filter with the unexceptional presence of D-elements, why is later on Ross's Left-Branch Condition acquired?

These questions will be dealt with in the next section.

\subsection{An alternative proposal}

None of the questions in (25) were relevant in the analysis of Hoekstra and Jordens (1994). Their answer on (25)a would be that the subextracted constituents are adjuncts not heads. If one would 
insist that the $<+/-w h>$ element is a functional category by force of Universal Grammar, they might grant that the subextracted constituent is a non-projecting D. Since it is non-projecting, it is at the same time maximal, hence a DP, see diagram (22). Their answer on (25)b is that subextraction of a head is impossible. Languages in which the $<+/-w h>$ element is reinterpreted as a projecting D do not allow the subextraction of the head D. They will move the DP which now includes the N-projection, see diagram (23). The constituent affected by move $<+/-w h>$ is a DP. Its landing site is the Spec, C. All of this is available if one accepts a learning scenario that starts with non-projecting functional categories but may retreat from that position due to new language specific evidence.

Let me now assume a learning scenario that recognizes functional categories and projects them automatically over their associated lexical complements. The advantages of this approach will be clear.

(26) a. There is no ambiguity of $<+/->$ projecting in functional categories.

b. There is no retreat from $<-$ projecting $>\mathrm{D} /$ Deg to $<+$ projecting $>\mathrm{D} / \mathrm{Deg}$.

These advantages for the learning scenario are available only if the UG theory of syntax is weakened.

Let me start with the first question in (25)a. The theory should allow the subextraction of functional heads. I tentatively propose that Minimality is to be futher relativized in such a way that a head $\mathrm{D}<+/-\mathrm{wh}>/<+\mathrm{N}>$ may cross a c-commanding head $<+\mathrm{V}>$ (cf. Roberts 1994). Only heads of the same A-/\} -type will cause a Minimality constraint. This should answer difficulty (25)a. See Van Kampen (1997:126f) for an elaboration.

The question in $(25) \mathrm{b}$ concerns the structure-preserving requirement (24)a. The chain caused by the long movement of the $\mathrm{D}<+/-\mathrm{wh}>$ could maintain the uniformity condition on chains if the $\mathrm{D}<+/-$ wh $>$ is adjoined to the head $\mathrm{C}$, where it could check on the $<+\mathrm{Q}>$ element. The subextracted element that adjoins to the $\mathrm{C}^{0}$ makes a chain that satisfies the requirements of uniformity, ccommand and feature checking in (24). A potential objection might be that the single pronoun in (27)a ends up in a landing site that is different from the subextracted operator.

a. $[\text { wat }]_{\text {Spec,C }}[\mathrm{ga}]_{+\mathrm{QCo}}$ jij $\mathrm{t}_{\mathrm{wh}}$ doen?

$$
\text { DP-chain }
$$

b. $[-]_{\text {Spec,C }}\left[\text { welk }[\mathrm{gaa}]_{\mathrm{Co}}\right]_{\mathrm{Co}}$ jij $\left[\mathrm{t}_{\mathrm{wh}}\right.$ boekje $]$ lezen?

$$
\mathrm{D}^{\mathrm{o}} \text {-chain }
$$

The overwhelming majority of wh-questions in the files is of type (27)a (single pronouns; see endnote 1). it seems plausible that the emergence of (27)b (subextraction) is caused by the clear presence of (27)a. However it is possible to change position (27)a into position (27)b by an additional step as follows. 
Let me assume the Head Cluster Principle in (28).m]13

\section{Head Cluster Principle}

Two adjacent heads that entertain a checking relation may adjoin to each other into a head cluster. The checked one adjoins to the one that checks.

This principle is string vacuous. It restructures the string, as in (29)b, and escapes from a violation of the uniformity condition (24)a.
a. [wat $]_{\text {Spec, }, \mathrm{C}}[\mathrm{ga}]_{+\mathrm{QCo}} \mathrm{jij}_{\mathrm{wh}}$ doen?
b. $\left[\mathrm{t}_{\mathrm{wh}}\right]_{\mathrm{Spec}, \mathrm{C}}\left[\text { wat }[\mathrm{ga}]_{\mathrm{Co}}\right]_{\mathrm{Co}} \mathrm{jij} \mathrm{t}_{\mathrm{wh}}$ doen?

There is some independent use for the Head Cluster Principle in clitic movement (Chomsky 1995:249). The long moved clitic binds an argument position, i.e. a maximal projection. The uniformity of the chain must be one of a maximal projection. As soon as the top of the argument chain cliticizes into the $\mathrm{V}^{\mathrm{o}}$, it turns into <-projecting > head 'at the last moment'. This again seems the restructering between two adjacent heads with a checking relation. Looking at the restructering in (29)b again, one may notice also that the relation between the incorporating head $\mathrm{C}^{\mathrm{o}}$ and the empty Spec,C reminds of the relation between the finite verb and the empty Spec,I in a pro-drop language. In sum, the Head Cluster Principle might answer the question in (25)b. The relation operator-argument is comparable to the relation clitic-argument.

The Left-Branch Condition, difficulty (25)c, does not follow from any of these arrangements. I speculate that the Case function of the D-element in pied-piping languages is in addition subject to a PF adjacency constraint between the D-element and its $\mathrm{N}$-complement. It is a nice point that this PF adjacency condition on Case-bearing elements derives independent support from a reanalysis of the Head-Final Filter in attributive APs (Van Kampen 1997:129f). In Van Kampen (1997:130f) I proposed that the $\mathrm{N}$-complement needs a string adjacent head $<+\mathrm{D}>$ in languages that obey the Left-Branch Condition.m]14 Latin and Polish N-projections by contrast do not need the Delement. They may violate the adjacency requirement when a D-element is present. The plus or minus PF adjacency requirement may be due to a Case-related parameter by the following speculation. Plausibly, N-elements in some languages are Case-marked due to the string adjacency of the D-element. In such languages a $\mathrm{D}^{0}$ is obligatorily present and string adjacent to each $\mathrm{N}$ if that constituent is to pass the Case Filter. In fact, the determiner is the spell-out of the Case feature (See Lebeaux (1988:242f) for a theory of Case assignment to $\mathrm{D}^{\circ}$ ). The parameter is formulated in (30).

$$
\begin{aligned}
& \text { Left-Branch Parameter } \\
& <+/->\mathrm{D}^{\circ} \text { dependent Case assignment to } \mathrm{N}
\end{aligned}
$$


It is reasonable to assume that the Polish/Latin type of grammar has N-projections with a selfsufficient Case paradigm. The parameter value of (30) is negative in this system. In these languages nouns need no formal D-elements. German, Dutch and English nouns, by contrast, do need D-elements to satisfy the Case Filter. In these languages nouns themselves have only a Case paradigm dependent on a context $<+\mathrm{D}>$. The parameter value of (30) is positive for these languages. They cannot subextract and they do apply pied piping obligatorily. The stipulations above imply that the Case Filter is a matter of PF after all.m]15

To summarize, $<+/-$ wh $>$ operators may be extracted from extended $<+\mathrm{N}>$-projections only if the latter are L-marked or marked under predication. The LAD obeys the CED (Condition on Extraction Domains, Huang 1982). It does not subextract out of subjects and adjuncts, cf. (17) and (18). This is consistent with recent locality theories. The fact that children do not comply with the language-specific Left-Branch Condition for a fairly long period is an issue of parameter setting. The parameter has been interpreted as involving a PF condition on Case marking. In Polish and kindred languages the checking of Case is not subject to PF adjacency with D-element, whereas it requires $\mathrm{D}^{\circ}$ adjacency in Dutch and German. In child language, the situation must be different. Rather, the Case-checking rules are not yet present as strict PF conditions and the adjacency of $\mathrm{D}^{\circ}$ $<+$ Case $>$ and $\mathrm{N}<-$ Case $>$ in child Dutch is not yet imposed by Case adjacency. Maybe this can be compared with the full acquisition of the Case endings in child Polish. The slow acquisition of Case conditions in Dutch ( $\mathrm{D}^{\circ}$ adjacency) and in Polish (N-suffixing) need not be unusual for a set of PF conditions.

\section{LF AND SUBEXTRACTION}

\subsection{The $<+$ wh $>$ subextraction}

In the last two sections I have suggested an answer to the question in (10)a. The learner of Dutch starts with a grammar not bounded by the Left-Branch Condition, because the initial grammar is not yet constrained by the PF adjacency requirement. A PF without pied-piping effects is closer to LF as it needs no reconstruction as I will consider below. This may explain why the acquisition of obligatory pied piping is remarkably slow. The subextractions find no support at all from the adult input and the learner progresses slowly towards the target language, since he/she is not informed

15.It is true that (30) does not account for the restrictions on the Deg $^{\circ}$ extractions in (i).

$\begin{array}{llll}\text { (i) hoe is } & \text { hij } & \text { groot? } \\ \text { how is } & \text { he } & \text { big? } \\ \text { (how big is he?) } & & \end{array}$

$\mathrm{D}^{\mathrm{o}}$ extractions arise from both the Left-Branch Parameter and LF primacy. Deg ${ }^{\circ}$ extractions only arise from the LF primacy. I will elaborate the LF primacy idea in section 7. It might be relevant that $\mathrm{Deg}^{\circ}$ extraction is allowed in some adult languages that do in general obey the Left-Branch Condition and are subjected to the Head-Final Filter (Cinque 1993b), for instance in Italian and South American Spanish (cf. the examples in (9)). Moreover, $\mathrm{Deg}^{\mathrm{o}}$ extractions seem to be more persistent in child language than $\mathrm{D}^{\mathrm{o}}$ extractions (Peter Coopmans p.c.). 
by negative evidence. The same slow fade-out is present in overgeneralizations of do-insertions in child language (Evers and Van Kampen 1995, Hollebrandse and Roeper 1996, Van Kampen 1997).

The idea that the subextractions are closer to the LF representation is in line with several recent proposals (Penner 1993, Thornton and Crain 1994, Penner and Weissenborn 1995, Van Kampen 1996 and others). Just like some other phenomena in child language, the wh-subextractions in child grammar may find support from the universal representation at LF. The LAD is enlightened by LF a priori's and corrected by PF input.

Let me make the familiar distinctions between an operator wh, a restriction $(\mathrm{N}, \mathrm{A})$ and a variable $t_{w h}$. The interpretation of the restriction has to take place in the position prior to wh-movement, in A-position. For architectural reasons Chomsky (1977:84) proposed that syntactic wh-movement must precede all semantic co-indexing rules.

$$
[\text { wh }(\text { restriction })]_{\mathrm{X}} \quad\left[\ldots \ldots . . \mathrm{t}_{\mathrm{wh}}(\text { restriction })\right]
$$

The wh-constituent moved into an A-bar position marks the scope of the question, but the restriction on the wh-operator picture of himself in (32) cannot be fully interpreted in that position.

$$
\text { [which picture of himself] does } \left.\mathrm{John}_{\mathrm{i}} \text { like [ } \mathrm{t}_{\mathrm{wh}} \text { picture of himself } \mathrm{f}_{\mathrm{i}}\right]
$$

The interpretation of the restriction in the trace position is crucial in (33) when Bill functions as the antecedent for himself.

[which picture of himself] John thinks that Bill $l_{\mathrm{i}}$ made [ $\mathrm{t}_{\mathrm{wh}}$ picture of himself $\mathrm{f}_{\mathrm{i}}$ ]

Chomsky proposed that the wh-constituent gets reconstructed at LF. The restriction part had to be moved back into the argument position occupied prior to wh-movement. Alternatively, but also by stipulation, the structure of the restriction part is preserved in the pre-wh position, and deleted later on.m]16 In view of this fairly complex arrangement, it is remarkable that the effect derived by LF reconstruction is directly present in the child's wh-subextractions.

For languages with overt movement, the wh-phrase requires reconstruction at LF.m]17 The sentences in (2)-(3) seem a direct reflection of LF, with the lexical argument in $\theta$-position and the functional element in scope-assigning position. For that reason, I suggest that the LF representation is immediately available to the learner and supports the wh-subextraction cases.

This accounts for the $<+w h>$ subextractions. The same kind of explanations holds for the $<-w h>$ subextractions (illustrated in (5)-(7)). The $<-w h>$ subextractions in child language also show an LF effect, as will be shown now.

16.See for variants and alternatives: Ruys (1993 and references cited there), Chomsky (1995:206ff).

17.See Hornstein and Weinberg (1990) for the idea that at LF quantifier raising and wh-raising move only the head. The same point is made in Lasnik (1993:29), for reasons of minimalist grammar. I adhere to the idea that operators are heads that may optionally pied pipe their lexical complement towards PF. Reconstruction (lowering) of the pied-piped complement is a countermovement towards LF. See for an elaboration Van Kampen (1997). 


\subsection{The $<-$ wh $>$ subextraction}

All subextractions of the D- and Deg-element in (5), (6) and (7) have a contrastive focus-marking function. There are two arguments for this claim.m]18

(34) a. The appearance of negative and positive focusing operators.

b. The contrastive stress on the D-/Deg-element.

The first argument ((34)a) is illustrated in (35) and (36). All examples involve a $<+/$-neg $>$ or $<+Q>$ focusing operator that marks illocution (wel 'indeed', niet 'not', nog 'yet', ook 'too', nou 'then').

(35) Contrastively focusing the $\operatorname{Deg}^{\mathrm{O}}$

$\mathrm{a}$ is heel wel [e lekker]!

is very indeed [e nice]!

((this) is very nice indeed)

c dat heb ikzo niet meer [ $e$ lang] gedaan!

(Loura 6;6)

that have I so not more [e long] done!

(I have not done that for a long time)

c. waarom moet dat zo nog [e heet]?

why must that so yet [e hot]?

(why does it have to be that hot yet?)

(36) Contrastively focusing the $\mathrm{D}^{\mathrm{o}}$
a. doejij Laura's ook [e haar]?
do you Laura'stoo [e hair]?
(are you fixing Laura's hair too?)
b. is andere nou [e puzzel]?
is other then [e puzzle]?
((where) is the other puzzle?)
c. K. gaatdie niet [e twee bananen] opeten
$\mathrm{K}$. goes that/those not [e two bananas] eat
d. jij kan mij niet [e muts] opdoen you can my not [e cap] on put (you cannot put my cap on) \\ (Sacha 3;7)
}
(Jasmijn 3;0)

(Tim B. 3;5)

A second argument $((34) b)$ that the $<-$ wh $>$ movements are instances of marked focus is provided by the contrastive value of the D-element in (37) in child language. The focus marking of the Delement has a contrastive effect and attracks non-neutral stress (for contrastive (disanaphoric) stress see Williams 1994). 


$$
\begin{array}{lllll}
\text { ik wil } & {[\text { díe }]_{i}} & \text { niet } & {\left[\mathrm{t}_{\mathrm{i}} \text { boek }\right]} & \text { lezen! } \\
\text { I want } & {[\text { thát }]_{\mathrm{i}}} & \text { not } & {\left[\mathrm{t}_{\mathrm{i}}\right. \text { book }} & \text { read! }
\end{array}
$$

(I do not want to read that book:

If there is a book I want to read, it is not that one)

The special stress on the element $\mathrm{D}^{\mathrm{o}} / \mathrm{Deg}^{\mathrm{o}}$ in (35) and (36) (heel 'very', zo 'so', dat/die 'that', Laura's 'Laura's', mij 'me'), as well as the presence of focusing operators indicate that the $\mathrm{D}^{\mathrm{o}} / \mathrm{Deg}^{\mathrm{o}}$ is interpreted as a contrastive element by the child. This fits into the analysis of Association with Focus as given by Von Stechow (1991).

The rule Association with Focus moves the focus to the immediate domain of the operator at LF. The examples in child language show a similar rule in the syntax, be it that only the $\mathrm{D}^{\mathrm{o}} / \mathrm{Deg}^{\mathrm{o}}$ element is in the domain of the focusing operator.m]19 A grammatical analysis in terms of LF and $\mathrm{X}$-bar representation of these items is as yet uncertain.m]20 I would like to suggest that the target of the subscrambled head is as follows (cf. (27)b).

$$
\begin{aligned}
& \{\text { is }\} \quad[-]_{\text {Spec,FP }} \quad\left[\left[\text { andere }[\mathrm{nou}]_{\mathrm{Fo}}\right]_{\mathrm{Fo}} \quad\left[. .\left[\begin{array}{llll}
\mathrm{DP} & \mathrm{D}^{\mathrm{o}} & {[\mathrm{N}}
\end{array}\right]\right] \ldots . . .\right]_{\mathrm{VP}} \\
& <+ \text { focus }><+ \text { focus }>\quad t_{\text {focus }}
\end{aligned}
$$

The focusing operator marks the constituent as $<+$ focus $>$. The contrastive element is adjoined to the head F, where it checks on the $<+$ focus $>$ element. The contrastive element is now in an operator position with respect to the predicate. This $<+$ focus $>$ analysis also accounts for the fact that articles in child Dutch, which are $<-$ focus $>$, will not subextract, whereas demonstratives $<+/$ focus $>$ may subextract. This is according to fact.

The LAD may receive input evidence from adult Dutch. In adult Dutch objects with a contrastive reading on the D-element may move out of the VP to the left of adverbial material. The sentence in (39) has a contrastive value, meaning something like 'don't want to read that one'.

$$
\begin{array}{lllll}
\text { ik } & \text { wil dát boek } & \text { niet } & \text { lezen } \\
\text { I want thát book niet } & \text { read }
\end{array}
$$

The contrastively focused DP ends up in an \}-position, as argued by Mahajan (1990) and Neeleman (1994).m]21 The LF representation separates the focus D-operator and the

19.Evidence of focus movement in the syntax and in violation of the Left-Branch Condition, has been registered in adult Bengali (Bayer 1994):

$\begin{array}{lllllll}\text { (i) } & \text { kalke } \quad \text { ama-r } & \text { baba } & -\mathrm{r} & -\mathrm{o} & \text { EkTa } & \text { notun baRi bikri hoe gEche } \\ \text { yesterday I-poss } & \text { father } & \text {-poss } & \text {-too } & \text { one } & \text { new house sell become went } \\ \\ \text { (yesterday a new house of my father too was sold) }\end{array}$


reconstructed N-complement.

To summarize, I have analyzed the $<-$ wh $>$ left-branch extractions as $\}$-movement triggered by $<+$ focus $>$. Languages differ as to whether they have the means of making the $\}$-raising operation visible in the syntax. From the present point of view it is significant that the effect obtained by LF reconstruction is directly present in child language as in the $<+w h>$ subextractions.

\section{CONCLUSION}

The initial questions in (10), repeated here in (40), have been answered as in (41).

(40) How is the Left-Branch Condition acquired?

a. Which parameter setting yields the Left-Branch Condition, that is which parameter setting forces pied piping?

b. Why does the learner of Dutch start with a grammar that lacks the Left-Branch Condition?

(41) a. A PF adjacency requirement.

b. A preference for a direct LF representation in PF.

Child grammar avoids reconstruction by applying subextraction. However, the subextractions seem to respect Huang's Condition on Extraction Domains. The CED as a universal constraint need not be learned. The Left-Branch Condition by contrast is not universal. I have proposed to derive it from a PF adjacency parameter.

The full acquisition of the pied piping parameter is as slow as the setting of a parameter can be. This longstanding alternative between subextracted and full movements implies an early optionality and its disappearance in a development from a superset language to a subset language. Moreover, the optionality does not disappear in Polish adult language. This clearly contradicts the Subset Principle which demands that acquisition is always accretional. Other parameter settings that contradict the Subset Principle are not rare at all as observed earlier by Lebeaux (1988:173ff). See for a discussion of optionality in acquisition along the lines of Lebeaux, in terms of computational economy, Van Kampen (1997:169ff). Constructions in child language that are not supported by adult input, may find support from the universal representation at LF. A more elaborated view of the influence of LF on child language acquisition would not fit in the present paper.

\section{ACKNOWLEDGEMENTS}

I am grateful to Judy Bernstein, Peter Coopmans, Martin Everaert, Arnold Evers, Aafke Hulk,

position. Scrambling in neutral contexts may be analyzed as movement to an A-position (Spec,AGRo in Mahajan 1990) or it may concern basegeneration in an A-position (Neeleman 1994). It lacks reconstruction effects. For neutral focus of non-scrambled definite objects see Reinhart (to appear). 
Fred Weerman, Ken Wexler, Frank Wijnen, two anonymous reviewers and the editors of this volume for valuable comments and disagreement. The research reported in this paper was supported by a grant (300-171-027) from the Netherlands Organization for Scientific Research (NWO).

\section{REFERENCES}

Abney, S.P.: 1987, The English Noun Phrase in its Sentential Aspect, Ph.D. dissertation, MIT.

Baker, M. C.: 1988, Incorporation. A Theory of Grammatical Function Changing, University of Chicago Press, Chicago.

Bayer, J.: 1994, 'Focusing particles: Aspects of their syntax and logical form', Paper presented at the 'Workshop on L1 and L2 Acquisition of Clause Internal Rules: Scrambling and Cliticization', January 21-23, Berne.

Butt, J. and C. Benjamin: 1988, A New Reference Grammar of Modern Spanish, Edward Arnold, London/New York.

Chomsky, N.: 1977, 'On wh-movement', in: P. Culicover, T. Wasow and A. Akmajian (eds.) Formal Syntax, 71-133, Academic Press, New York.

Chomsky, N.: 1986, Barriers, MIT Press, Cambridge Mass.

Chomsky, N.: 1995, The Minimalist Program, MIT Press, Cambridge Mass.

Cinque, G.: 1993a, 'A null theory of phrase and compound stress', in: Linguistic Inquiry 8.3, 425504.

Cinque, G.: 1993b, 'On the evidence of partial N movement in the Romance DP, ms. University of Venice.

Corver, N. F. M.: 1990, The Syntax of Left-branch Extractions, Ph.D. dissertation, Tilburg University.

Demske, U.: 1995, 'Prenominal genetive phrases as definite determiners', ms. University of Tübingen/Stuttgart.

Emonds, J.: 1985, A Unified Theory of Syntactic Categories, Foris, Dordrecht.

Evers, A. and N.J. van Kampen: 1995, 'Do-insertion and LF in child language', in: J. Don, B. Schouten, W. Zonneveld OTS Yearbook 1994, 24-41, Utrecht University.

Fukui, N. and M. Speas: 1986, 'Specifiers and projections', MIT Working Papers in Linguistics 8, 128-171.

Giusti, G.: 1995, 'A unified structural representation of (abstract) case and article', in: H. Haider et al. (eds.) Studies in Comparative Germanic Syntax, 77-93, Kuwer, Dordrecht.

Haegeman, L.: 1992, 'Sentential negation in Italian and the Neg Criterion', ms. University of Geneva.

Hoekstra, T. and P. Jordens: 1994, 'From adjunct to head', in: T. Hoekstra and B. D. Schwartz (eds.) Language Acquisition Studies in Generative Grammar, 119-149, John Benjamins Publishing Company, Amsterdam/Philadelphia.

Hollebrandse, B. and T. Roeper: 1996, 'The concept of $d o$-insertion and the theory of INFL in acquisition', in: Ch. Koster and F. Wijnen (eds.) Proceedings of GALA 1995, September 7-9.

Hornstein, N. and A. Weinberg: 1990, 'The necessity of LF', in: The Linguistic Review 7, 129-167. 
Huang, J. C.-T.: 1982, Logical Relations in Chinese and the Theory of Grammar. Ph.D. dissertation, MIT.

Kampen, N.J. van: 1994, 'The learnability of the left-branch condition', in: R. Bok-Bennema and C. Cremers (eds.), Linguistics in the Netherlands 1994, 83-94, John Benjamins Publishing Company, Amsterdam/Philadelphia.

Kampen, N.J. van: 1996, 'PF/LF convergence in acquisition', in: K. Kusomoto (ed.) Proceedings of the North Atlantic Linguistic Society 1995 (NELS 26), October 23-27, 149-163.

Kampen, N.J. van: 1997, First Steps in Wh-movement, Ph.D. dissertation, Utrecht University.

Lasnik, H.: 1993, 'Lectures on minimalist syntax', ms. University of Connecticut.

Lattewitz, K. T.: 1997, Adjacency in Dutch and German, Ph.D. dissertation, Groningen University.

Lebeaux, D.: 1988, Language Acquisition and the Form of Grammar, Ph.D. dissertation, University of Massachusetts

Longobardi, G.: 1996, 'The syntax of N-raising: A minimalist theory', ms. Utrecht University.

Mahajan, A.: 1990, The A/\}-Distinction and Movement Theory, Ph.D. dissertation, MIT, Cambridge Mass.

Neeleman, A.: 1994, Complex Predicates. A Comparative Analysis of Dutch and English VerbPredicate Constructions. Ph.D. dissertation, Utrecht University.

Penner, Z.: 1993, 'The earliest stage in the acquisition of the nominal phrase in Bernese Swiss German: Syntactic bootstrapping and the architecture of language learning', Arbeitspapiere 30, Universität Bern, Institut für Sprachwissenschaft.

Penner, Tracy and Weissenborn: this volume, 'Where scrambling begins: Triggering object scrambling at the early stage in German and Bernese Swiss German'.

Penner, Z. and J. Weissenborn: 1995, 'Strong continuity, parameter setting and the trigger hierarchy: On the acquisition of the DP in Bernese Swiss German and High German', in: H. Clahsen (ed.) Generative Perspectives on Language Acquisition, John Benjamins Publishing Company, Amsterdam/Philadelphia.

Radford, A.: 1986, 'The acquisition of the complementizer system', in: Bangor Research Papers in Linguistics 2, 55-76.

Reinhart, T.: 1995, 'Interface strategies', OTS Working Papers, Utrecht University

Rivero, M.-L. de: 1991, 'Long head movement and negation: Serbo-Croatian vs. Slovak and Czech', in: The Linguistic Review 8, 319- 351.

Rizzi, L.: 1990a, 'Speculations on verb second' in: J. Mascaró and M. Nespor Grammar in Progress, 375-386, Foris, Dordrecht.

Rizzi, L.: 1990b, Relativized Minimality, MIT Press, Cambridge Mass.

Roberts, I.: 1994, 'Two types of head movement in Romance' in: N. Hornstein and D. Lightfoot (eds.) Verb Movement, 207-242.

Ross, J. R.: 1967, Constraints on Variables in Syntax, Ph.D. dissertation, MIT.

Ruys, E. G.: 1993, The Scope of Indefinites, Ph.D. dissertation, Utrecht University.

Stechow, A. von: 1991, 'Focusing and backgrounding operators', in: W. Abraham (ed.) Discourse Particles, Proceedings of the Workshop at the Goningen University 1986, May 24-26, Benjamins, Amsterdam.

Szabolsci, A.: 1983, 'The possessor that ran away from home', The Linguistic Review 3, 89-102. 
Thornton, R. and S. Crain: 1994, Successful cyclic movement, in: T. Hoekstra and B.D. Schwartz Language Acquisition Studies in Generative Grammar, 215-252, John Benjamins Publishing Company, Amsterdam/Philadelphia.

Uriagereka, J.: 1988, On Government, Ph.D. dissertation, University of Connecticut, Storrs.

Williams, E.: 1994, Thematic Structure in Syntax, Linguistic Monographs 23, MIT Press, Cambridge Mass.

Wit, P. de: 1997, Genetive Case and Genetive Constructions, Ph.D. dissertation, Utrecht University. 